Ротань В.Г., Очкуренко С.В. ПРАВОВЫХ ЯВЛЕНИЙ

Rotan V.G., Ochkurenko S.V.

\title{
THE LEGAL NATURE OF THE MORTGAGE (THE GUARANTEE) AND ITS DELIMITATIONS FROM THE ADJACENT CIVIL AND LAW PHENOMENON
}

В статье обосновывается понимание сущности залога как комплекса обязательственных отношений. Абсолютные (вещные) правоотношения по поводу залога имеют сугубо вспомогательное значение, а поэтому не могут выражать сущность залога. Неразрешенность в науке вопроса о характере залога обусловлена тем, что дискуссия о характере залога либо ведется вообще в отрыве от норм права, регулирующих залоговые отношения, и правоотношений, возникающих в результате такого урегулирования, либо не учитывает в достаточной мере содержание соответствующих законодательных положений. Предполагаемое включение положений об ипотеке в раздел II Гражданского кодекса отрицательно скажется на структуре Гражданского кодекса.

Залог следует отличать от смежных правовых явлений. В частности, предоставление залогодержателю (кредитору по обеспеченному залогом обязательству) право на удовлетворение своего требования за счет источников, перечисленных в п. 2 ст. 334 ГК, не означает, что соответствующие права и правоотношения, содержание которых составляют эти права, включаются в правовую конструкцию залога. Даже и предоставление управомоченному лицу, в интересах которого был наложен запрет на распоряжение имуществом, прав залогодержателя на заложенное имущество, не является основанием для признания правоотношения, в содержание которого входит это право, входящим в правовую конструкцию залога.

Ключевые слова: залог, правоотношения по поводу залога, преимущественное право, обязательственная сущность залога, специальная правовая норма, вещные элементы залога.

In this article it substantiates the understanding of the sense of the mortgage (the guarantee) as the complex of the liability law. The absolute (of estate) law relationships apropos of the mortgage (the guarantee) have especially auxiliary significance. And this is why they cannot express the essence of the mortgage (the guarantee). There is an insolubility of the question on the character of the mortgage (the guarantee) in the science. It is caused by this: the discussion on the character of the mortgage (the guarantee) is implementing in principle out of touch of the standards of law, which regulate the mortgage (the guarantee) relationships and out of law relationship, appearing as a result of such regulation or this discussion does not take into account in the appropriate measure the content of the corresponding law statements. The supposed inclusion of the statements on the mortgage (guarantee) in part II of the Civil Code will negatively influence the structure of the Civil Code.

We have to differ the mortgage (the guarantee) from the adjacent law phenomenon. In particular the assignment to the mortgagee (creditor on the obligation, which is secured by the mortgage (the guarantee) of the right to satisfy its requirement at the expense of sources, enumerated in paragraph 2 of the article 334 of the Civil Code does not mean that the appropriate rights and law 
relationships, which are the matter of these rights, are included in the law construction of the mortgage (the guarantee). Even the allocation to the legal person, in interest of which the restriction to dispose the property was imposed, the rights of mortgagee on the mortgaged property, is not the reason to recognize the law relationships, which content has this right, which is the part of the construction of the guarantee (the mortgage).

Keywords: the mortgage, the law relationships apropos of the mortgage (the guarantee), the law of preference, the liability essence of the mortgage (the guarantee), the special legal standard, estate elements of the mortgage (the guarantee).

Залог как способ обеспечения исполнения обязательств является незатратным для должников, которые обычно являются залогодателями, и надежным для кредиторов (залогодержателей). Поэтому он широко используется в гражданском обороте в условиях рыночной экономики. При социализме он почти не использовался. Это и обусловило определенную новизну залога для современной российской науки гражданского права, для современного российского гражданского права и практики его применения. В новых экономических условиях наука обратилась к исследованию залога, активизировалась правотворческая деятельность, направленная на регулирование залоговых отношений, неизмеримо возросло количество рассматриваемых судами гражданских дел, связанных с залогом. Однако в течение короткого времени все теоретические, правотворческие и правоприменительные проблемы залога не были решены, что и обусловливает актуальность темы, обозначенной в заглавии настоящей статьи.

Залог в разное время был предметом исследования дореволюционных российских ученых-специалистов в области гражданского права Л.В. Гантовера, Д.И. Мейера, К.П. Победоносцева, К.Н. Анненкова, Г.Ф. Шершеневича. В новейшее время вопросы залога исследовались в работах Б.М. Гонгало, В.В. Витрянского, В.А. Белова, Р.С. Бевзенко, Д.В. Дождева и других ученых.

Целью настоящей статьи является постановка и попытка решения некоторых теоретических проблем понятия залога, имеющих непосредственное практическое значение.

Легальное определение понятия залога дается в п. 1 ст. 334 ГК. В этом определении указывается на право залогодержателя (кредитора) по обеспеченному залогом обязательству получить удовлетворение из стоимости заложенного имущества преимущественно перед другими кредитора лица, которому принадлежит заложенное имущество(залогодателя). Очевидно, «право получить удовлетворе- ние... преимущественно перед другими...» без вреда для юридического содержания приведенной формулировки может быть интерпретировано как преимущественное право на получение указанного удовлетворения. Тогда залог в своей сущности должен быть отнесен к ближайшему роду преимущественных прав. Однако недостаточная исследованность преимущественных прав создает затруднения и для познания залога, в том числе и для определения понятия залога.

В.А. Белов уже длительное время держит в зоне своего внимания проблему преимущественных прав (по крайней мере, с 2001 года, когда была опубликована его статья на эту тему [1]). Но залог к категории преимущественных прав он не относит [2, с. 898-909], что выглядит не вполне логичным, поскольку сам законодатель признает право залогодержателя на преимущественное удовлетворение своего соответствующего требования. Да и сам В.А. Белов пишет: «Аналогичное право - преимущественного получения удовлетворения принадлежит залогодержателю в отношении страхового возмещения, уплаченного в случае гибели или повреждения предмета залога» [3, с.352]. Выходит, что автор и залог признает преимущественным правом (поскольку аналогичное залогу право является преимущественным).

Однако идти за В.А. Беловым в данном случае вряд ли будет целесообразным, поскольку он преимущественные права признает принадлежащими к роду прав секундарных, что является движением не к истине, а в противоположном направлении. Преимущественные права - это не секундарные, а субъективные права, ибо им, преимущественным правам, корреспондируют обязанности. «Иначе в случаe Gestaltungsrecht: праву одной стороны соответствует не обязанность другой стороны, а только связанность ее этим правом», - писал М.М. Агарков [4, с. 280]. При этом он поясняет, что в случаях, когда Gestaltungsrecht заключается в выборе кредитором одного из альтернативных обязательств, указанная связанность су- 
ществует в обязательстве, возникшем в результате выбора кредитора уже как обязанность, которой корреспондирует право кредитора требовать исполнения указанной обязанности, а не Gestaltungsrecht (секундарное право). Секундарные права - это права на собственные юридические действия. Они не могут нарушаться, а потому не могут и защищаться. А преимущественные права могут нарушаться, следовательно, - могут защищаться судом.

Представляется, что преимущественными указанные несколько выше субъективные права назвали в силу потребности как-то указать на способ разрешения коллизий между специальными правовыми нормами, устанавливающими такие права, с одной стороны, и конкурирующими с ними общими правовыми нормами, - с другой. Суть проблемы заключается в том, что законодатель совершенно утратил веру в способность и практикующих юристов и ученых квалифицировать соотношение между соответствующими правовыми нормами как соотношение между общими и специальными нормами и разрешать коллизии между ними. Поэтому в данном случае он указал на то, что право (субъективное право) залогодержателя является преимущественным (право получить удовлетворение своего требования преимущественно перед другими кредиторами). В других случаях он указывает на применение общих норм только при отсутствии специальных (п. 1, 2 ст. 307.1.; п. 4 ст. 334; п. 2, 5 ст. 454; ст. 625 ГК и т.д.), подсказывая юристам, как разрешать соответствующие коллизии в законодательстве.

В.А. Белов считает, что «преимущественные права могут возникнуть у субъектов только в случаях, предусмотренных законом» [2, с. 895]. Казалось бы, что уже указания законодателя в соответствующих случаях на преимущественный характер права соответствующего лица достаточно для признания его преимущества этого лица перед другими лицами. Но В.А. Белов пишет, что «упомянутое преимущество объясняется тем, что обсуждаемая возможность, будучи секундарным правом, обладает более высокой степенью конкретизации, чем аналогичные возможности - элементы правоспособности - других лиц, таким правом не обладающих. Игнорирование этого преимущества дает обладателю секундарного права, относящегося к разряду преимущественных, право на иск о переводе на себя прав и обязанностей, возникших в результате реализации посторонними лицами своей гражданской правоспособности в обход его преимущественного права (особый преобразовательный иск)» [2, с. 894]. Тем самым автор цитированного научного положения признает, что преимущественный характер соответствующего права обусловливается содержанием правовой нормы, которая его устанавливает: она в большей мере конкретизирует предоставленную субъекту преимущественного права возможность, чем норма, предоставляющая лицу правоспособность. Все привыкли к правилу «lex spezialis derogat generali», и вдруг нам предлагается заменить или дополнить это правило новым. Специальная правовая норма в ее соотношении с общей определяется не степенью конкретизации предоставляемой ею возможности, а более узкой сферой действия, чем сфера действия общей нормы. При этом сфера действия специальной правовой нормы не должна выходить за пределы действия общей нормы. Сфера действия правовой нормы определяется достаточно широко понимаемой гипотезой правовой нормы. А предоставляемая правовой нормой управомоченному лицу возможность определяется диспозицией правовой нормы. Поэтому предложенное В.А. Беловым преимущественное применение нормы, которая конкретизирует предоставляемую управомоченному лицу возможность - это даже и не модификация правила «lex spezialis derogat generali», a введение в науку и право вообще совершенно нового правила о преимуществе при правоприменении норм по критерию конкретизации предоставляемых ими управомоченным лицам возможностей. Мы не будем оспаривать такое новшество, но вводить его мимоходом в теорию права и практику правоприменения нельзя. Это надо обдумывать и обсуждать.

Что касается защиты преимущественного права иском о переводе прав и обязанностей, да еще и применения такого способа защиты в тех случаях, когда такой способ специально не предусмотрен (об этом пишет В.А. Белов [2, с.896]), то по этому поводу необходимо заметить следующее. Во-первых, законодатель имеет право устанавливать любые правовые конструкции. И это в полной мере касается правовой конструкции перевода прав и обязанностей. Без этой правовой конструкции вполне ведь можно было обойтись, но законодатель пришел к выводу о целесообразности законодательного признания такой правовой конструкции. Во-вторых, абстрактно рассуждая, предъявляемые в суде требования о при- 
знании недействительной сделки, нарушающей преимущественное право, и о понуждении нарушителя преимущественного права к заключению договора с субъектом преимущественного права на соответствующих условиях отличаются от требования о переводе прав и обязанностей по договору, нарушающему преимущественное право, на субъекта преимущественного права только несколько большей громоздкостью, затрагивающей внешнюю форму, а не юридическую сущность указанных требований. По юридической сущности два названных выше первыми требования тождественны требованию о переводе прав и обязанностей. Поэтому не следовало бы и видеть в преимущественных правах содержание, которого в них нет, и абсолютизировать значение перевода прав и обязанностей как способа защиты преимущественных прав. А именно из такой абсолютизации и исходит В.А. Белов, когда он пишет, что «возможность судебного перевода прав и обязанностей, возникших из факта пренебрежения связанного преимущественным правом лица своим состоянием связанности, должна рассматриваться в качестве способа реализации охраняемых законом интересов, возникающих при нарушении любых преимущественных прав» [2, с. 896]. Приходится лишь удивляться, с какой легкостью предлагается применять перевод прав и обязанностей по договору в случаях, когда законодатель этого не предусмотрел, но когда применимыми могут быть общие правила о способах защиты права.

Поскольку специальные правовые нормы подлежат преимущественному применению перед не совместимыми с ними общими правовыми нормами, другие лица (не наделенные преимущественным правом в силу специальных правовых норм) также могут претендовать на удовлетворение своих требований за счет заложенного или удерживаемого имущества, на заключение договора, являющееся объектом преимущественного права, но только после удовлетворения субъектом преимущественного права (права, установленного специальной нормой) своего требования за счет соответствующего имущества или после его отказа от заключения договора. Поскольку не совместимые с общими специальные нормы подлежат преимущественному применению, основанные на них субъективные права также назвали преимущественными. При этом следовало бы учесть, что указанная несовместимость обусловлена тем, что специальная право- вая норма предоставляет определенное право, которое может быть реализовано только одним лицом, узкому кругу лиц (или в случае с залогом - только определенному лицу), а общая - любому лицу или во всяком случае - более широкому кругу лиц.

Законодатель мог бы не закреплять преимущественное право соответствующих лиц, а наделить их ординарным субъективным правом и указать при этом, что предусматривающая такое субъективное право норма гражданского права подлежит преимущественному применению перед соответствующими общими правовыми нормами. Это касается и п. 1 ст. 334 ГК, устанавливающего специальную правовую норму и соответствующее преимущественное право залогодержателя.

Обозначение некоторых субъективных прав, установленных специальными правовыми нормами, как преимущественных или указание на преимущественную реализацию таких субъективных прав перед субъективными правами других лиц создает иллюзию того, что называемые преимущественными права являются сложными и в свою структуру включают относительное субъективное право (естественно, существующее в соответствующем относительном правоотношении) и абсолютное субъективное право, которое существует в соответствующем абсолютном правоотношении и в соответствии с которым управомоченное лицо вправе требовать от каждого не препятствовать в осуществлении указанного выше субъективного права.

Но такой возможности субъекту так называемого преимущественного права закон не предоставляет. Поэтому лицо, обладающее преимущественным правом в относительном правоотношении, воздействовать на третьих лиц может только косвенно: через предъявление соответствующих требований к должнику. Это утверждение не опровергается тем обстоятельством, что ответчиками по иску о переводе прав и обязанностей по договору, нарушающему преимущественное право, будет не только лицо, несущее обязанность заключить договор с субъектом, наделенным преимущественным правом, а и другая сторона договора, которым нарушено преимущественное право. Обязанность, корреспондирующую преимущественному праву, несет только залогодатель, лицо, отчуждающее долю в праве общей собственности, и другие соответствующие лица. Другая сторона договора, которым нарушается преимущественное право, никаких обязанностей перед

\section{3}

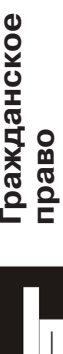


субъектом преимущественного права не несет, действует при заключении такого договора в силу права, входящего в содержание ее правоспособности. Следовательно, преимущественные права, в том числе и право залога, не могут быть признаны абсолютными (в соответствующих случаях - вещными) только потому, что субъект преимущественного права имеет преимущество перед третьими лицами, ибо преимущество имеет любой субъект, которому право предоставлено специальной правовой нормой, перед субъектом, право которого основано на общей правовой норме.

Из легального определения залога в п. 1 ст. 334 ГК, которое выше уже приводилось, Р.С. Бевзенко делает такой вывод: «...Залог - это особое ограниченное вещное право, содержанием которого является право его обладателя (залогодержателя) присвоить себе в счет погашения обеспеченного долга стоимость предмета залога преимущественно перед другими кредиторами залогодателя» [5, с. 240]. Содержание права залогодержателя раскрыто здесь в точном соответствии с п.1 ст. 334 ГК. Но названо это право ограниченным вещным совершенно произвольно: п.1 ст. 334 ГК оснований для такого вывода не дает. Правовые формы удовлетворения залогодержателем своего требования из стоимости заложенного имущества в п.1 ст. 334 ГК не определяются. Это законодательное положение допускает такое удовлетворение в правовой форме обязательства в той же мере, как и в форме вещных правоотношений. А определить эту правовую форму возможно только путем анализа и соответствующей квалификации правоотношений, нормативным основанием которых являются законодательные положения о залоге. Но в науке гражданского права не принято использовать категорию правоотношений как методологическое средство познания содержания соответствующих законодательных положений и последующего формулирования теоретических выводов. В моде - абстрактные рассуждения (в данном случае, - о вещном или обязательственном характере залога).

Вещные правоотношения по поводу залога действительно могут возникать. В.А. Белов появление у залога элементов, которые должны быть квалифицированы как вещные права, не без оснований связывает с возникновением у залогодержателя правомочий владения и пользования и возможности их защиты. Но он неправильно утверждает, что в правомочии владения (а в соответствующих случаях - и в правомочии пользования) заключается «сущность залогового права» [3, с. 353]. Сущность залогового права раскрыта в п. 1 ст. 334 ГК, и полагаем, что спорить об этом излишне. А правомочия владения и пользования, которые в соответствующих случаях получает залогодержатель, в правовой конструкции залога имеют сугубо вспомогательный характер и не могут выражать сущность залогового права. В то же время важно подчеркнуть, что вещные права (владения и пользования предметом залога), которые получает в соответствующих случаях залогодержатель, входят в содержание именно правовой конструкции залога, а не выходят за ее пределы, как это имеет место в правовой конструкции аренды, в которой арендатор получает права владения и пользования (или только пользования), а осуществляет их в соответствующих вещных (абсолютных) правоотношениях, в чем В.А. Белов успешно убедил своих читателей [6, с. 30-33].

Мысль об абсолютной или вещной (в соответствующих случаях) сущности (природы) залога, является весьма распространенной в юридической науке. Она возникла из иллюзии того, что залогодержатель вправе отстранить любое лицо от предмета залога и удовлетворить свое, обеспеченное залогом требование за счет предмета залога. Но залогодержатель права на такое «отстранение» не имеет. Право принимать меры, необходимые для защиты заложенного имущества от посягательств и требований со стороны третьих лиц, залогодержатель получает только при условии, что он владеет заложенным имуществом (подпункт 4 п. 1 ст. 343 ГК). А в остальных случаях залогодержатель имеет лишь права, которые осуществляются путем предъявления требований к залогодержателю. Эта последняя мысль - не новая. Российский ученый цивилист Л.В. Гантовер сформулировал ее еще в конце XIX века [7, с. 396-397].

Автор настоящей статьи готов даже упрекнуть сторонников признания абсолютной (вещной) природы залога в недобросовестности. Не исключено, что Бог дал им возможность увидеть вещные элементы залога, которые для автора настоящей статьи являются непостижимыми. Тогда они должны довести увиденное до сведения коллег по науке, показать соответствующие абсолютные (вещные) правоотношения, права и обязанности, момент их возникновения, изменения, прекращения. Коллеги усвоят этот урок и тоже увидят вещную природу залога. Но ведь такие правоотношения, права и обязанно- 
сти, их динамику никто никогда не раскрывал. В дискуссии о природе залога упрека заслуживают именно сторонники абсолютной (вещной) природы залога, утверждающие, что они что-то видят, но не желающие (или не могущие) объяснить, что же они видят. А противники абсолютной (вещной) природы залога добросовестно признаются, что они не видят абсолютных (вещных) признаков в сущности правоотношений по поводу залога. Суть проблемы, как представляется, в склонности ученых-юристов вести дискуссию на сугубо абстрактном уровне даже тогда, когда речь идет об интерпретации положений нормативных правовых актов (без перехода на уровни правовых норм, правоотношений, субъективных прав и корреспондирующих им обязанностей).

Очевидно, в дискуссии об абсолютной (вещной) или обязательственной природе залога следует уточнить значение термина «абсолютное (вещное) право». Его никак нельзя видеть в появлении отношения лица к вещи (иному объекту абсолютного права), в конкретизации или даже индивидуализации вещи (иного объекта) как предмета обязательства. Такое отношение (лица к вещи) для квалификации права как вещного является необходимым, но оно не является достаточным. Во-первых, такое отношение должно быть непосредственным (а не опосредованным требованием к должнику). Во-вторых, абсолютное (вещное) право существует только тогда, когда праву определенного лица на соответствующее благо корреспондирует обязанность неопределенного круга лиц не нарушать указанное право. Но такой обязанности в сущности правовой конструкции залога не существует. Поэтому в праве залогодержателя на получение удовлетворения из стоимости заложенного имущества преимущественно перед другими кредиторами и даже в его праве требовать передачи ему предмета залога (в праве оставить предмет залога у себя) абсолютного (вещного) содержания не больше, чем в праве приобретателя вещи по договору требовать отобрания вещи на основании ст. 398 ГК.

Любой термин является условным, или, как пишет В.А. Белов, «термины носят конвенциональный, договорный характер» 8 , с. 109]. Но все-таки не стоило бы доводить условность терминов до абсурда, когда вещный характер признается за правовыми конструкциями, которые подчас вообще не имеют в своем содержании вещных правоотношений. В свое время, безусловно, в полной мере заслуживший тех высших похвал, которые были высказаны в его адрес нашим современником [9, с. 7], И.А. Покровский очень неудачно отнес к вещным право на получение лицом известной ценности из вещи (залоговое право) и «разнообразные права на приобретение известной вещи или известных вещей» (в частности, право преимущественной покупки) [10, с. 206207]. Все-таки, как общее правило, в своей сердцевине правовая конструкция залога не содержит в себе ни одного вещного правоотношения: «Залог прежде всего рождает ограничение собственника относительно распоряжения имуществом. Но ограничение собственника относительно распоряжения вещью не составляет еще для другого лица права на эту вещь, а только стесняет объем самого права собственности. Далее, при неисправности лица обязанного залогоприниматель вправе требовать продажи залога и из выручки получить удовлетворение. Но и это право требовать продажи залога нельзя признать правом на чужую вещь, потому что право требовать продажи вещи отнюдь не содержится в праве собственности, тогда как право на чужую вещь именно является вырезком из права собственности в пользу другого лица: в праве собственности содержится право отчуждения, но не это право принадлежит залогопринимателю, а ему принадлежит только право требовать, чтобы надлежащее присутственное место подвергло заложенное имущество продаже» [11, с. 438-439]. Подчеркнем, что мы ведем речь об общем правиле и абстрагируемся от случаев, когда залогодержатель действительно получает вещные права на заложенную вещь в правоотношениях, которые в правовой конструкции залога имеют сугубо вспомогательное значение. Что касается права преимущественной покупки, то оно никак не может осуществляться через какие-либо вещные правоотношения. Неудачную попытку С.А. Синицына доказать вещную природу преимущественных прав в своей еще аспирантской статье [12] Е.А. Суханов оценил, однако, как убедительное обоснование вещной природы права приобретения чужой недвижимой вещи, которая (упомянутая вещная природа) «не вызывает сомнений» [13, с. 145]. Но в провинции (в отличие от столицы) - все же вызывает.

Чтобы как-то оправдать признание ипотеки вещным правом, авторы проекта Федерального закона «О внесении изменений в часть первую Гражданского кодекса Российской Федерации», к настоящему времени прошедшего первое чтение в Государственной Думе, указали на 
право залогодержателя распорядиться заложенной недвижимой вещью в порядке и на условиях, определенных законом и договором ипотеки. Но даже и признание права залогодержателя распорядиться предметом ипотеки еще не означает, что ипотека приобрела вещный характер: В.А. Белов не без оснований усомнился в логичности включения правомочия распоряжения в содержание права собственности (и, надо полагать, - в содержание любого вещного права) [3, с. 109]. Поэтому признание права распоряжения входящим в правовую конструкцию залога, в угоду признанию залога вещным правом, очевидно, потребует пересмотра самой конструкции вещного права и права собственности.

В силу специального указания в положении абзаца второго п.1 ст. 334 ГК («В случаях и в порядке, которые предусмотрены законом, требование залогодержателя может быть удовлетворено путем передачи предмета залога залогодержателю (оставления у залогодержателя)») понятием залога охватывается также право залогодержателя на передачу ему предмета залога или на оставление у него этого предмета (с целью получения удовлетворения его соответствующего требования).

В то же время предоставление в соответствии с п.5 ст. 334 ГК прав и возложение обязанностей залогодержателя на кредитора или иное управомоченное лицо, в чьих интересах был наложен запрет на распоряжение имуществом, не дает оснований для квалификации прав такого кредитора или иного управомоченного лица как залога. Предоставление прав и возложение обязанностей залогодержателя в этом случае не изменяет первоначальной отраслевой и институциональной принадлежности правоотношений, возникших на основании упомянутого запрета. Законодатель даже вроде бы попытался ограничить возможность предоставления прав и возложения обязанностей залогодержателя на указанное лицо, но сделал это крайне неудачно: допустил такое предоставление или возложение, если иное не вытекает из существа залога. Но существо залога не может никогда препятствовать предоставлению прав и возложению обязанностей залогодержателя на участников любых отношений, если только это не противоречит существу последних (а не существу залога).

Р.С. Бевзенко, специально исследовавший институт залога, пишет, что арест очень похож «на залог, правда, устанавливаемый не в силу предписания закона или положения договора, а по решению суда. И дальнейшая логика законодателя также свидетельствует о том, что права кредитора, по чьему требованию был наложен арест, крайне похожи на права залогодержателя» [5, с.250]. «Крайне похожи» - с этим нельзя не согласиться. Но в то же время Р.С. Бевзенко считает, что в п.5 ст. 334 ГК речь идет о залоге в силу ареста, а «идея, согласно которой арест имущества должника порождает залоговое право, характерна для многих правопорядков и признается в актах унификации частного права (ст. IX.-4:107 Модельных правил европейского частного права)» [5, с.250]. Но в ГК РФ эта идея на сегодня не признана. Речь идет о необходимости более точной квалификации правоотношений. Автор настоящей статьи однажды отнес цитированного и подвергаемого здесь критике автора к той категории ученых-юристов, которые обладают высокой культурой мышления. Обнаруживается, однако, что Роман Сергеевич грешит и недостаточным вниманием к букве закона и склонностью насилия над той буквой закона в случаях, когда которой он уделил достаточное внимание.

Еще больше, чем арест, законодатель отдалил от залога права залогодержателя на удовлетворение своего обеспечиваемого залогом требования за счет страхового возмещения и других источников, перечисленных в п.2 ст. 334 ГК. В пункте первом этой статьи устанавливается, что в силу залога залогодержатель вправе удовлетворить свое требование из стоимости заложенного имущества или путем передачи ему предмета залога. А пункт второй той же статьи дает залогодержателю получить удовлетворение своего требования «также» за счет страхового возмещения и других источников, названных в этом пункте (помимо удовлетворения из стоимости заложенного имущества или путем получения этого имущества в собственность). Слово «также» дает основания интерпретировать п. 1 и 2 ст. 334 ГК таким образом, что лицу, являющемуся залогодержателем, дается право на удовлетворение своего обеспеченного залогом требования из стоимости заложенного имущества, путем приобретения права собственности на заложенное имущество (это - в силу залога), а также (не в силу залога, а в силу специальных правовых норм) за счет видов имущества, которые перечислены в п.2 ст. 334 ГК. Слово «также» выводит права залогодержателя на удовлетворение своего требования за счет имущества, указанного в п.2 ст. 334 ГК, за пределы залога. 
Р.С. Бевзенко, однако, увидел в п. 2 ст. 334 ГК такое явление как эластичность залога «... Залог - это право на ценность заложенного имущества, то как бы ни изменялась внешняя форма, в которой существовала в момент установления залога эта ценность, залог сохраняется до тех пор, пока будет существовать фактический или юридический заменитель этой ценности» [5, с.244]. Полагаем, что п.2 ст. 334 ГК оснований для подобного рода вывода не давал. Р.С. Бевзенко увлекся экономическим содержанием соответствующих отношений и игнорировал их правовую форму.

Неправильная квалификация права залогодержателя на удовлетворение своего обеспеченного залогом требования за счет источников, указанных в п.2 ст.334 ГК, влечет дальнейшие ошибки при разрешении правовых коллизий. Так, Р.С. Бевзенко рассматривает условный пример, когда заложенный и застрахованный автомобиль попал в аварию, и страховщик перечислил страховое возмещение на залоговый счет страхователя. Он полагает, что «в данном случае принцип эластичности уступит более фундаментальному правовому принципу - невозможности ухудшения правового положения одного лица действиями других лиц без его на то согласия» [5, с.354]. Автор свел коллизию между правовой нормой, дающей залогодержателю право на получение удовлетворение за счет источников, указанных в п.2 ст.334 ГК, и правовой нормой, которая вытекает из п. 1 ст. 334 и п. 1 ст.358.9 ГК и определяет содержание прав залогодержателя прав по договору банковского счета, к коллизии между двумя принципами, один из которых является более фундаментальным. Все-таки вводить в научный оборот правило о разрешении коллизии между правовыми принципами по критерию степени их фундаментальности можно было бы, если бы это правило было сформулировано на достаточном эмпирическом материале. Но автор не отсылает к научным публикациям такого рода, собственным или иных авторов. Поэтому создается впечатление, что приведенное правило сформулировано на базе одной - единственной коллизии и только для ее разрешения. Полагаем, так делать нельзя.

Выше цитировалась мысль Р.С. Бевзенко, в соответствии с которой в силу эластичности залога он сохраняется до тех пор, пока существует юридический или фактический заменитель ценности заложенного имущества. Мы критически оценили эту мысль ученого. Но он-то сам от нее не отказывался. Поэтому и должен был разрешать рассматриваемую коллизию по критерию старшинства залогов, имея в виду, что очередность удовлетворения требований залогодержателей определяется в зависимости от момента возникновения каждого залога (п.1 ст. 342.1 ГК). Другое дело, что правило о старшинстве залогов для целей разрешения рассматриваемой коллизии вообще не может применяться, как и нельзя прямо разрешать коллизию между п. 1 ст. 334 и п.1 ст. 358.9 ГК, с одной стороны, и абзацами первым-пятым п.2 ст. 334 ГК. Препятствием для последнего является положение абзаца шестого п.2 ст. 334 ГК: «В случаях, указанных в абзацах втором-пятом настоящего пункта, залогодержатель вправе требовать причитающиеся ему денежную сумму или иное имущество непосредственно от обязанного лица, если иное не предусмотрено законом...». Вывод a contrario из этого законодательного положения дает нам правовую норму, в соответствии с которой залогодержатель не вправе требовать денежную сумму или иное имущество от иного лица, если такое право не предоставлено ему законом. И эта оговорка придает указанной норме, логически закрепленной в абзаце шестом п.2 ст.334 ГК, способность к конкуренции при правоприменении. Но использовать вывод a contrario при толковании права среди юристов считается даже менее приличным, чем поступить так, как поступил один ученый, обозвавший юридическую науку словом, используемым для обозначения представительниц древнейшей профессии, а ученых - словом, обозначающим как бы бизнесменов, торгующих этими самыми представительницами как товаром.

Но все-таки указанная норма в абзаце шестом п.2 ст. 334 ГК логически закреплена, и именно она препятствует реализации залогодержателем своего права на денежные средства, на которые указано в абзацах втором-четвертом п.2 ст. 334 ГК, если они уже были зачислены на залоговый счет.

Что касается оговорки «если иное не предусмотрено ... договором», содержащейся в п.2 ст. 334 ГК, то термин «договор» следует толковать так, как он понимается в главе 27 ГК «Понятие и условия договора», то есть как регулятор отношений между его сторонами, что подтверждается ст. 156 ГК: сделка может создавать обязанности для других лиц лишь в случаях, установленных законом либо соглашением с этими лицами. С учетом изложенного термин «договор» в п.2 ст. 334 ГК 
следует понимать как договор с участием соответствующего лица (владельца залогового счета).

Таким образом, определение понятия залога в п.1 ст. 334 ГК вполне позволяет отграничить залог от смежных гражданско-правовых явлений, если только субъекты правотолкования будут проявлять достаточное внимание и уважение к букве закона.

В этой статье были затронуты только те признаки залога, в которых выражается его сущность. Дальнейшие исследования залога целесообразно было бы посвятить всей системе залоговых правоотношений.

\section{Литература}

1. Белов В.А. Основы учения о преимущественных правах // Вестник МГУ. Серия «Право». - 2001. - № 6. - С. 37-54.

2. Белов В.А. Гражданское право. T. IV. Относительные гражданско-правовые нормы. - М.: Юрайт, 2013. - 1085 с.

3. Белов В.А. Гражданское право. Т. ІІІ. Особенная часть. Абсолютные гражаднско-правовые формы. - М.: Юрайт, 2013. - 1189 с.

4. Агарков М.М. Избранные труды по гражданскому праву. В 2-х т. Т.І. - М.: ЦентрЮрИнфор, 2002. - 490 с.

5. Договорное и обязательственное право (общая часть): постатейный комментарий к статьям 307-453 Гражданского кодекса Российской Федерации / Под ред. А.Г. Карапетова. - М.: Статут, 2017. - 1120 с.

6. Белов В.А. Очерки вещного права. Научно-полемические заметки: учебное пособие для бакалавриата и магистратуры. - М.: Юрайт, 2015. - 332 с.

7. Брагинский М.И., Витрянский В.В. Договорное право. Общие положения. - М.: Статут, 1997. - 682 с.

8. Гражданское право: актуальные проблемы теории и практики / Под ред. В.А. Белова. - М.: Юрайт, 2007. - 993 с.

9. Маковский А.Л. Выпавшее звено. Вступительная статья / Покровский И.А. Основные проблемы гражданского права. - М.: Статут, 2016. - С. 7-40.

10. Покровский И.А. Основные проблемы гражданского права. - М.: Статут, 2016. - 351 с

11. Мейер Д.И. Русское гражданское право. - М.: Статут, 2000. - 831 с.

12. Синицын С.А. Вещная природа преимущественных прав // ЗаконодательСтво. - 2008. - № 10.

13. Гражданское право: учебник: В 4 т. Т. ІІ. / Отв. ред. Е.А. Суханов. - М.: Статут, 2019. - 464 с.

\section{References}

1. Belov V.A. Osnovy ucheniya o preimushchestvennyh pravah // Vestnik MGU. Seriya «Pravo». - 2001. - № 6. - P. 37-54.

2. Belov V.A. Grazhdanskoe pravo. T. IV. Otnositel'nye grazhdansko-pravovye normy. - M.: YUrajt, 2013. - 1085 p.

3. Belov V.A. Grazhdanskoe pravo. T. III. Osobennaya chast'. Absolyutnye grazhadnsko-pravovye formy. - M.: YUrajt, 2013. - $1189 \mathrm{~s}$.

4. Agarkov M.M. Izbrannye trudy po grazhdanskomu pravu. V 2-h t. T.I. - M.: CentrYUrInfor, 2002. - $490 \mathrm{p}$.

5. Dogovornoe i obyazatel'stvennoe pravo (obshchaya chast'): postatejnyj kommentarij k stat'yam 307-453 Grazhdanskogo kodeksa Rossijskoj Federacii / Pod red. A.G. Karapetova. - M.: Statut, 2017. - 1120 p.

6. Belov V.A. Ocherki veshchnogo prava. Nauchno-polemicheskie zametki: uchebnoe posobie dlya bakalavriata i magistratury. - M.: YUrajt, 2015. - 332 p.

7. Braginskij M.I., Vitryanskij V.V. Dogovornoe pravo. Obshchie polozheniya. - M.: Statut, 1997. -682 p.

8. Grazhdanskoe pravo: aktual'nye problemy teorii i praktiki / Pod red. V.A. Belova. - M.: YUrajt, 2007. - 993 p.

9. Makovskij A.L. Vypavshee zveno. Vstupitel'naya stat'ya / Pokrovskij I.A. Osnovnye problemy grazhdanskogo prava. - M.: Statut, 2016. - P. 7-40.

10. Pokrovskij I.A. Osnovnye problemy grazhdanskogo prava. - M.: Statut, 2016. $351 \mathrm{p}$.

11. Mejer D.I. Russkoe grazhdanskoe pravo. - M.: Statut, 2000. - 831 p.

12. Sinicyn S.A. Veshchnaya priroda preimushchestvennyh prav // Zakonodatel'stvo. - 2008. - № 10 .

13. Grazhdanskoe pravo: uchebnik: V 4 t. T. II. / Otv. red. E.A. Suhanov. - M.: Statut, 2019. - $464 \mathrm{p}$.

РОТАНЬ Владимир Гаврилович, доктор юридических наук, професcop, профессор кафедры «Гражданское право и процесс» Юридического института, Севастопольский государственный университет. 299053, Российская Федерация, г. Севастополь, ул. Университетская, 33. E-mail: rotan1942@mail.ru 
ROTAN Vladimir, Doctor of Juridical Science, Professor, Professor of the Department «Civil Law and Process» of Law Institute, Sevastopol State University. 299053, Universitetskaya str., 73, Sevastopol, Russian Federation. E-mail: rotan1942@mail.ru

ОЧКУРЕНКО Сергей Владимирович, доктор юридических наук, доцент, заведующий кафедрой «Финансовое и банковское право» Юридического института, Севастопольский государственный университет. 299053, Российская Федерация, г. Севастополь, ул. Университетская, 33. E-mail: sevlas@list.ru

OCHKURENKO Sergei, Doctor of Juridical Science, Associate Professor, Head of the Department «Financial and Banking Law» of Law Institute, Sevastopol State University. 299053, Universitetskaya str., 73, Sevastopol, Russian Federation. E-mail: sevlas@list.ru 